\title{
EFFECTIVE CONDITIONS OF CHILDREN'S ADAPTATION TO THE EDUCATIONAL CONDITIONS IN PRIMARY SCHOOL
}

\section{Iryna Bartienieva}

Candidate of Pedagogical Sciences, Senior Lecturer at the Department of Pedagogy, South Ukrainian National Pedagogical University named after K. D. Ushynsky, Ukraine e-mail: irina021271@ukr.net, orcid.org/0000-0003-3420-2965

\section{Oksana Nozdrova}

Candidate of Pedagogical Sciences, Senior Lecturer at the Department of Pedagogy, South Ukrainian National Pedagogical University named after K. D. Ushynsky, Ukraine e-mail: katenozdrova654@gmail.com, orcid.org/0000-0003-2988-7912

\author{
Agnieszka Kamtoh \\ MA, Polonia University in Czestochowa, Interdisciplinary Faculty, Poland \\ e-mail: akamtoh@ap.edu.pl,orcid.org/0000-0002-3930-8278
}

\section{Summary}

The article deals with the actual topic of adaptation of six-year-old children to the conditions of school education. The essence of the concepts "adaptation", "social adaptation", "psychological adaptation", "adaptation to school" is determined. A theoretical analysis of the topic under study is presented. The factors of disadaptation of children to school are revealed. Indicators of the child's socio-psychological adaptation to school (the formation of adequate behavior, establishing contacts with classmates and teachers, mastering the skills of educational activities) are formulated. The conditions for the successful adaptation of children to school life have been identified. The directions and principles of the activity of the teaching staff of the elementary school for the adaptation of six-year-old children to the conditions of school education are considered. The stages of psychological and pedagogical support of adaptation of first-graders to school are described. It is substantiated that the continuity of the methods of work of the institution of preschool education and primary school is a necessary condition for the adaptation of children to school. One of the effective forms of ensuring continuity and creating psychological comfort for a child's stay in an educational institution is educational complexes.

It has been proven that readiness for school is one of the conditions for the successful adaptation of children to school. A model of a psychological portrait of an adapted first-grader is presented, taking into account the pedagogical, intellectual, motivational, emotional-volitional, communicative readiness.

Keywords: six-year-old children, successful adaptation, readiness for school, adapted child, psychological and pedagogical support of a first grader.

DOI https://doi.org/10.23856/3921

\section{Introduction}

Going to school makes a big great change in a child's life. The period of adaptation to primary school is very difficult for first graders. They master a new social role of a pupil, a new type of activity - educational, the social environment changes - classmates, teachers, school as a social group appear, their way of life changes. 
One of the conditions for successful adaptation to school life is children's readiness for school. The research of many psychologists and teachers (K. Abulkhanova-Slavskaya, B. Almazov, G. Ball, L. Vygotsky, N. Gutkina, I. Dubrovina, T. Dorozhevets, S. Kozlov, M. Maksimova, A. Petrovsky, J. Piaget, S. Stepanov, L. Phillips, T. Shibutani, G. Zuckerman and others) deals with this problem. The authors provide not only an analysis of the necessary knowledge, skills and abilities of a child during the transition from kindergarten to school, but also discuss about ways of differentiated approach in preparing children for school, methods for determining readiness, ways to correct negative results and, in this regard, recommendations for working with children and parents.

The successful solution of the problems of the development of the child's personality, the increase in the effectiveness of education is largely determined by how correctly the level of children's readiness for schooling is taken into account.

A child who enters school must be mature in physiological and social terms, attain a certain level of mental and emotional-volitional development. Taking into account the increasing psychological and pedagogical literacy of teachers and parents, more and more attention is paid to the development of the child's personality, his moral and psychological well-being, preparation for school education and adaptation to primary school.

Currently, the problem of adaptation of children to school is very relevant due to the fact that many first-graders are six-year-old. The year that separates a six-year-old child from a seven-yearold is very important for his physical, functional (psychophysiological) and mental development.

\section{Presentation of the main research material}

Age of six years is a period when intensive morphological and functional rearrangements of organs and systems occur, and school workload can negatively affect the psychophysiological state of the child and create difficulties in adapting to learning in primary school conditions.

A child who enters an educational institution does not become a schoolboy immediately. During the period of adaptation at school, which takes from one month to one year, the previous experience of the child's relationship with those around him, the usual stereotypes of his behavior are transformed in accordance with the new conditions (Grigorovich L., Migushkin A., 2000).

Adaptation can be considered as a special phase in the formation of a person, on which the nature of his further personal development largely depends. Adaptation - accommodation of children to the conditions and requirements of the new environment. Its result is adaptation as a personal quality, which is an indicator of the child's vital competence, his ability to orientate himself and influence others.

Social adaptation is an integrative indicator of a person's state, that reflects his ability to perform certain biosocial functions: adequate perception of the surrounding reality and his own organism; an adequate system of relations and communication with others; ability to work, study, organization of leisure and recreation; the ability to self-service and mutual service in the family and team, variability (adaptability) of behavior in accordance with role expectations.

Psychological adaptation - the adaptation of a child as a person to existence at school in accordance with his own requirements and personal needs, motives and interests. It is carried out by mastering the norms and values of the school team.

Adaptation to school is the restructuring of the cognitive, motivational, emotional and volitional spheres of the child during the transition to systematic organized schooling. Children with sufficient communication experience, with developed speech, formed cognitive motives and skills of volitional regulation of behavior, easily adapt to school conditions.

The model of school adaptation includes academic adaptation, social adaptation, and personal adaptation. 
The main indicators of a child's social and psychological adaptation to school are the formation of adequate behavior, establishing contacts with classmates and a teacher, mastering the skills of educational activities.

Factors that can cause maladjustment include: partial retardation and impairment in physical development; delay and specificity of mental, personal development; signals of distress, which indicate a delay in the adaptation period (physiological problems; disturbances in habitual forms of behavior, mood; unwillingness to go to school; neurosis; fears; persistent deviations in personal development); violation of discipline, irresponsibility; unfavorable family environment.

School is the second most important (after the family) institution of socialization of the child. The development of the personality of a primary school student is influenced not only by family values, rules and foundations, but also, to a large extent, by the content of social norms and traditions. School requirements are recognized as mandatory and important not only by the children themselves, but also by their parents, who expect a full compliance with the model from the first grader.

An important aspect of the adaptation of a first grader is taking on a new social role - the role of a pupil. The effectiveness of adaptation largely depends on how adequately the child perceives himself and his relationship with other people. It is necessary to take into account the individual characteristics of the child (Rimashevskaya L., 2007).

The signs of successful adaptation are the child's satisfaction with the learning process; the degree of assimilation of the program; the degree of independence in performing educational tasks; satisfaction with interpersonal relationships with classmates and teacher.

The condition for the successful adaptation of six-year-old children to school is their readiness for schooling. It is considered as a complex characteristic of a child, which reveals the levels of development of psychological qualities, which are the most important prerequisites for normal inclusion in a new social environment and for the formation of educational activity.

The types of readiness include pedagogical, personal, moral, intellectual, motivational, communicative, emotional-volitional, physical, speech, socio-psychological readiness. There are three aspects of school maturity: intellectual, emotional, social.

The main tasks of psychological and pedagogical preparation of six-year-old children for school are: dynamic development of mental processes (perception, memory, thinking, imagination), improvement of basic types of activity; teaching children the methods of "processing" the material of cognition: assignment of objects, phenomena based on similarities, differences; development of mental operations: analysis, synthesis, comparison, abstraction, concretization, generalization, classification, independent judgments, etc.; teaching children the methods of examination for the purpose of rational cognition of the surrounding reality; the formation of cognitive abilities: accuracy and fragmentation of perception, the ability to easily grasp the distinctive features of objects, the ability to understand difficult situations, highlight the main thing in them, to plan own actions; the formation of the prerequisites for educational activity and its characteristic features: the ability to listen and hear adults, work under their directions; the ability to separate his own actions from those of other children; the formation of relations between a child and others in order to satisfy his need for personal communication and common activities with adults.

A theoretical analysis of the problem of adaptation of six-year-old children to school conditions has shown the need for a formative experiment to study the effective adaptation conditions for first-graders and to develop a methodology for the successful adaptation of children to school.

Let us consider the directions of activity of the teaching staff of the school at the initial stage of teaching first-graders, children of six-year-old. 
An adapted child is a child adapted to the full development of his personal, physical, intellectual and other potentials in the given pedagogical environment (Shirokova G. (Ed.), 1998).

The task of psychological and pedagogical support during this period is to create pedagogical and socio-psychological conditions that allow the child to function and develop successfully in the educational environment.

The system of psychological and pedagogical support for the adaptation of first graders to school included the following stages: organizing the work of the «School of the Future First Grader» with preschoolers; diagnostics of the readiness of preschoolers for schooling; individual consultations and meetings with parents of future first graders; accompanying first graders at the stage of primary adaptation to school; monitoring the results of adaptation of primary schoolchildren.

The organization of work of the "School of the Future First Grader" was carried out in the following directions: acquaintance of children with the school and its territory (excursion); meeting with teachers; development of fine and gross motor skills (special classes and exercises); physical education; development of intellectual abilities; preservation of the emotional well-being and mental health of children.

The child's adaptation to school will be all the more successful the more actively his family is involved in education. Therefore, it was planned to work with the parents of future first-graders in order to increase the psychological and pedagogical competence in those directions that are most relevant from the point of view of the period of development experienced by children. These are thematic parenting workshops "Preparing for school in the game", "Is my child ready to go to school?", "Portrait of a future first grader". Meetings are held in the form of "family councils", consultations, dialogues, relying on the existing experience of parents.

Without exaggeration, we can call the period of adaptation of children at school the most difficult for parents and the most responsible for children. We have developed recommendations for parents on the successful adaptation of children to primary school.

Psychological and pedagogical work with schoolchildren with increased and high levels of anxiety was carried out during the second half of the 1st grade.

Purpose: to identify and eliminate those moments in the educational process, in the style of pedagogical communication with children, which can provoke various school difficulties.

A group psycho-corrective work was organized with schoolchildren who have difficulties in learning, behavior and communication with teachers and peers. When monitoring mental health, the most significant signs influencing behavior deviation were followed: aggressiveness; self-rating; anxiety.

Educating and consulting teachers on teaching and communicating with individual pupils, was organized taking into account their individual characteristics.

It is necessary to determine the type of temperament to which the child belongs: choleric, sanguine, phlegmatic, melancholic.

Choleric. In appearance, this is an energetic and active child, but he can be hyperactive. The main feature is that the process of excitation prevails over the process of inhibition. It is difficult for such a child to calm down if he "got out" during the game or to switch from vigorous activity to class. It is difficult for such children to restrain emotional impulses, they cannot keep still. Parents of such children should follow such recommendations:

- to find a school where there is a teacher who practices game methods at the initial stage of learning, this will greatly facilitate the adaptation to the school;

- to work intensively with the child to accustoming him to the regulation of time and actions to train him.

Sanguine. An active child, with high efficiency, does not get tired during games or classes, easily switches from one to another, is not inclined to get depressed. As to possible adaptation problems, they are the same as in children - choleric. 
Phlegmatic person. Slow reactions prevail in this type of temperament. They manifest themselves in the tempo of speech, in the manner of movement, in poor and flowing gestures. But this is a strong type of temperament, he has a high working capacity. He does not immediately get involved in any business. But, having started work, he will study assiduously, attentively and thoughtfully. Such a child will calmly endure thirty - forty minutes. But he may have difficulties: if the lesson is going at a fast pace, then the phlegmatic child will not always perceive the proposed material. Accordingly, he will lag behind in understanding and assimilating the material, slowly respond to the teacher's questions. In the case of a phlegmatic child, it is recommended to select exercises that are based on long-term work alone, and on interaction, it is better to arrange a competition with parents, according to the scheme "Who will answer faster", "Who will decide better". With the help of such activities, parents make it easier for him to adapt to the pace of school.

Melancholic. The weakness of the nervous system is manifested in low efficiency, rapid fatigability, high sensitivity. As a result, the melancholic is very vulnerable in communication and in interaction with the outside world. Due to his weakness, the melancholic can hardly withstand any stress - not only long-term and intense mental, emotional and mental stress, but also conflicts that he experiences especially strong and acute. Discipline problems usually do not arise with this type of temperament.

Individual, group counseling and education of parents was carried out based on the results of tracking the adaptation of first graders.

The activity of the teaching staff of the school in this direction was based on the principles (Karabakva O., 2004): psychological comfort (creation of a special subject-developing environment that provides emotionally comfortable conditions for the educational process); activities (the possibility of independent discovery, performing actions aimed at studying objects and phenomena; the development of fine motor skills of the hand); creativity (the opportunity to gain experience of one's own creative activity); continuity (preschool propaedeutic base); visibility (in accordance with the age-related psychophysical characteristics of children).

The main goal of this activity is to create a general favorable background for the development of children: physical, intellectual, emotional. In accordance with this goal and the principles stated earlier, the activities of the teaching staff in organizing a favorable adaptive environment were aimed at: maximizing the physical activity of children at school; the creation of a developing object environment at school, which is, in fact, a continuation of the one that children are accustomed to in kindergarten and which is distinguished by brightness, colorfulness, clarity, the inclusion of play and fairy-tale motives in it; wide use of play techniques in educational and upbringing work, the creation of emotionally significant situations and conditions for independent practical activity; changing the style of interaction between adults and children from authoritarian to the style of trusting cooperation; introduction into the pedagogical process of various types of children's creative activity; the use of diverse forms of education; ensuring the relationship of educational activities with life; creation of a sparing regime of educational activities.

In addition, in working with first-graders, the teaching staff paid great attention to the valeological direction in order for children to go through the adaptation period without damage to their health, without losing interest in learning, without losing faith in themselves and in their strengths.

An important condition for the mental and physical health of schoolchildren was a markfree system in grades 1-2. It is mark-free but, not rating-free. Establishing a good, trusting relationship between teacher and children was of particular importance.

The teacher can and shall, according to R. Burns, provide the child a way to assimilate the formal knowledge taught in school, which would not harm his self-appraisal. And in relation to a child with negative self-image, the teacher's goal is to transform these ideas, using the 
possibilities of subject learning and various situations that arise in school, to install in the child a sense of his own worth, competence and significance.

V. Zinchenko developed a methodology for enhancing the intersubjective interactions of pupils on the basis of their inclusion in communicative situations, which reflects the logic of the gradual formation of social activity. This methodology is based on: the formation of social trust of first-graders to each other; development of social emotions in first graders; the formation of the ability to defend their own position in the process of communication; development of communication skills of pupils.

To overcome the alienation between children, we also advised teachers to use games that help raise the child's rating in the eyes of their peers and establish emotional contact between them.

In carrying out these games, it is necessary to entrust the "isolated" children with the role of the leader in the game, praise the child in front of the whole group, and note how well he coped with the role of the leader.

The development of emotional and communication skills in children was facilitated by their acquaintance with various emotional experiences; learning to recognize emotions; training in arbitrary expression of various emotional states; games for the development of communication skills.

For the successful adaptation of first graders, senior preschoolers and primary school pupils, we proposed a series of fairy tales, which consisted of five "Forest Tales". The children were looking forward to the proposed fairy tales about the heroes from the «Forest School», talking about the actions of the heroes, understanding their reasons, learning to forgive and love.

Thus, the thoughtful, cohesive, purposeful activity of the teaching staff at the initial stage of teaching children of six years of age in the first grade contributed to their successful adaptation to the conditions of schooling.

We believe that the continuity of the methods of work of the institution of preschool education and primary school is a necessary condition for the adaptation of children to school.

The importance of adhering to the principle of consistency in the education system is beyond doubt. In educational activities, this principle is implemented through the consistency and systematic placement of educational material, in education as in a process that combines organically related stages: preschool education, education in primary school, basic and high school.

"Primary school should very accurately and fully consider the achievements of preschool age, not only in terms of content and methodology, but also in terms of the formation of individual abilities of children, their volitional sphere", says O. Savchenko.

One of the effective and efficient forms of ensuring continuity in the educational activities of preschool and primary school institutions, creation the psychological comfort of a child's stay in an educational institution are educational complexes, which have a number of advantages.

An important role in the adaptation of a child to school play the continuity of the methods of work and pedagogical communication between the kindergarten teacher and primary school teachers who work with children of six years of age. The fact is that one of the frequent reasons for the difficulties in adapting six-year-old children to school is a sharp change in the style of communication between a teacher and children. Even with a positive attitude towards children, the teacher often uses more rigid, authoritarian forms of pedagogical influence than those to which preschoolers are accustomed. These forms of pedagogical influence are often perceived by the child as an expression of personal hostility, which leads to passivity, suppresses initiative, independence, gives rise to self-doubt (especially in timid, shy children).

Improving work with children of six years of age presupposed a revision of the forms of influence by teachers so that they did not contrast with the communication style of the kindergarten teacher. For this it was necessary: 
1. Conducting meetings, seminars, conferences, teachers' councils for the exchange of experience of kindergarten teachers and school teachers working with first graders.

2. A visit by teachers of a kindergarten school, supervision over the organization and management of various types of activities of children (play, educational, labor, artistic, household) and, accordingly, a visit by kindergarten teachers of a school with subsequent analysis, discussion, exchange of experience.

Socio-psychological characteristics for each child and the group as a whole, compiled by the educator of the senior group and passed on to them by the primary school teachers, is another important way to deepen this continuity.

3. Establishing a connection between kindergarten and school can also go along the line of developing contacts between kindergarten pupils and school students (patronage of the kindergarten, joint educational activities).

We offered a program of classes in a preschool education institution aimed at preparing children for successful school education (psychological readiness).

Thus, within the framework of continuity for the successful organization of work with children of senior preschool age to prepare them for primary school, it is necessary to take into account the following recommendations: the formation of psychological readiness for school involves a combination of play, productive, educational and other types of activity; to achieve efficiency in teaching six-year-old children, it is necessary to form a positive, emotional attitude to knowledge; to ensure the relationship of the content of classes with the daily life of children, their independent activities (play, art, etc.); create a developing subject environment, both in kindergarten and primary school; use play methods more widely in elementary school, create emotionally significant situations, conditions for independent practical activity, when children can, on the basis of their knowledge, show initiative, creativity, fantasy; recognize the child's right to proactive statements and reasoned defense of their proposals; the leading should be a dialogical form of communication between an adult and children, which contributes to the development of the child's activity, initiative, self-rating and self-esteem.

Let's give an example of a psychological portrait of an ideal first grader.

1. Pedagogical readiness: reading skills; counting skills; writing skills; drawing skills; sound culture of speech (pure broadcasting); the ability to fully answer a question; large vocabulary; general awareness.

2. Intellectual readiness: differentiation of perception as the basis of thinking; systematic perception (observation); developed imagination; the ability to navigate in space and time; developed scientific and imaginative thinking (the ability to highlight those that are significant in the phenomena of the surrounding natural environment, the ability to compare and see their similarity and difference); developed fine motor skills (use of a pencil, pen, scissors, drawing skills); good memory; developed regulatory function of language (the ability to follow verbal instructions); intellectual activity (the ability to turn an educational task into an independent goal of activity); prerequisites for abstract-logical thinking (the ability to understand symbols and, when formulating a question, independently reason, find the causes of phenomena, draw simple conclusions).

3. Motivational readiness: expressiveness of cognitive interests; an attempt to assimilate the role of the pupil (the desire to go to school), acceptance of the system of requirements put by the school and the teacher.

4. Emotional-volitional readiness: the ability to manage one's own behavior; preservation of efficiency during one lesson and school day; emotional resilience (regulation of emotions); voluntary regulation of attention (concentration, resilience, switching); the ability to 
restrain his own your impulses (for example, not to interrupt others during a conversation); the ability to continue the action, making volitional efforts to this.

5. Communicative readiness: desire to communicate with adults and children; the ability to establish contacts with the teacher; maintaining a sense of distance; ability for personal contact with adults; the ability to establish contact with peers; the ability to enter the children's team and find his own place in it; the ability to do work together; ability to maintain equal relationships with classmates.

\section{Results of the research}

As a result of the experimental work, the number of children with a high level of adaptation increased (from $32 \%$ to $39 \%$ ). There were almost no changes in the control group. In this group, the number of children with a low level of adaptation decreased by $1 \%$ (from $37 \%$ to $36 \%$ ), the average indicator increased by $1 \%$ from (33\% to $34 \%$ ). Such a slight change is explained by the fact that experimental purposeful work was not carried out in the control group.

We managed to achieve that in the experimental group the number of children with a low level of adaptation decreased by $16 \%$ (from $41 \%$ to $25 \%$ ), the number of children with an average level of adaptation increased by $9 \%$ (from $27 \%$ to $36 \%$ ), by $7 \%$ the indicator of a high level of adaptation increased (from $32 \%$ to $39 \%$ ).

\section{Conclusions}

The conducted research does not claim to be a complete consideration of all aspects of adaptation of six-year-old children to school conditions. The importance of the problem dictates the need to search for other pedagogical conditions that have a beneficial effect on adaptation.

\section{References}

Grigorovich L., Migushkin A. (2000). Osobennosti razvitiya uchebnoj motivacii u detej 6 - 7 let [Features of the development of educational motivation in children 6-7 years old]. [in Russian] Karabakva O. (2004). Organizaciya adaptivnoj sredy na nachalnom etape obucheniya [Organization of an adaptive environment at the initial stage of training]. [in Russian]

Shirokova G. (Ed.). (1998). Preemstvennost v rabote detskogo sada i nachalnoj shkoly [Continuity in the work of kindergarten and primary school]. Moscow. [in Russian]

Rimashevskaya L. (2007). Socialno-lichnostnoe razvitie [Social and personal development]. [in Russian] 